DDS. School of Dentistry Heminio Ometto University Center UNIARARAS. Dr. Maximiliano Baruto, 500. Araras-SP. 13607-339, Brazil.taozaniboni@hotmail.com

PhD. School of Dentistry Heminio Ometto University Center, UNIARARAS. D Maximiliano Baruto, 500 ArarasSP 13607-339. Brazil mario@ vedovelloeassociados.com.br

${ }^{3} \mathrm{PhD}$ Division of Periodontics, School of Dentistry, State University of São Paulo, UNESP. Av. Eng Francisco Jose Longo, 777. São José dos Campos - SP 12245-000 Brazi mauro.santamaria@fosjc.unesp.br

${ }^{4} \mathrm{PhD}$. Division of Periodontics, School of Dentistry, State University of São Paulo, UNESP.Av. Eng. Francisco Jose Longo, 777. São José dos Campos - SP. 12245-000, Brazil mauro.santamaria@fosjc.unesp.br

${ }^{5} \mathrm{PhD}$. Department of Oral Pathology, Bauru Dental School, University of São Paulo, USP. Alameda Otávio Pinheiro Brisolla, 9-75. Vila Universistária. Bauru-SP 17012-901, Brazil.mfmartinsortiz@gmail.com

${ }^{6} \mathrm{PhD}$. Department of Oral Pathology, Bauru Dental School, University of São Paulo, USP. Alameda Otávio Pinheiro Brisolla, 9-75. Vila Universistária. Bauru-SP. 17012-901 Brazil.consolaro@uol.com.br

PhD. School of Dentistry Heminio Ometto University Center, UNIARARAS. Dr. Maximiliano Baruto, 500 Araras-SP 13607-339,

Brazil santamariajr@ig.com.br

Corresponding author: Milton Santamaria J Heminio Ometto University Center, UNIARARAS. Dr. Maximiliano

Baruto, 500 Araras-SP

13607-339, Brazil

Received: January 14, 2017

Accepted: November 23, 2017

\section{Root morphology can be a risk factor for periodontal damage and root resorption in orthodontic movement}

Ewerton Zaniboni ${ }^{1}$, Mário Vedovello Filho², Mauro Pedrine Santamaria ${ }^{3}$, Maria Aparecida Neves Jardini ${ }^{4}$, Maria Fernanda Martins-Ortiz ${ }^{5}$, Alberto Consolaro ${ }^{6}$, Milton Santamaria $\mathrm{Jr}^{7 *}$.

Aim: The study evaluated, using histomorphometry, the percentage of hyaline area in periodontal ligament (PDL) and root resorption in orthodontic tooth movement (OTM). Methods: Ten rats were divided into two groups. G3 Group $(n=5)$, with 3 days of OTM and G7 Group ( $n=5)$, with 7 days of OTM. A Control Group $(n=5)$ consisted of contralateral teeth of each animal, which were not moved. Maxillary left first molar was moved, using stainless steel spring connected to the incisors with $40 \mathrm{~g}$ force. Microscopic analysis was done in transversal sections of the mesiovestibular (MV) and distovestibular (DV) roots in the cervical level. Results: There was a PDL hyaline area in the DV root of $6.2 \%$ in G3 and $1.8 \%$ in G7. The root resorption area in G7 was $0.9 \%$. On MV root and Control Group were not found occurrences of hyaline areas in PDL and no root resorption. Conclusions: Based on the results obtained, it might be concluded that smaller roots showed higher frequency of hyaline areas and root resorption.

Keywords: Tooth movement. Periodontal ligament. Root resorption. Orthodontics. 


\section{Introduction}

The complexity of events in orthodontic tooth movement (OTM) involves forces of compression and traction on the periodontal ligament (PDL) and alveolar bone, inducing morphological and microscopic reactions controlled by cytokines and growth factors, promoting tooth displacement ${ }^{1-4}$.

In orthodontics, a mechanical stimulus induces tooth movement ${ }^{5-6}$. The orthodontic force causes an imbalance in PDL, an inflammatory process ${ }^{7-8}$ where cytokines produced by osteoclasts, osteoblasts and osteocytes control bone remodeling around PDL ${ }^{9-10}$.

Experimental studies allow clinical and microscopic evaluation of the tooth movement biology and root resorption. Different aspects may interfere in the effectiveness of OTM, such as the intensity and type of force applied, local and systemic diseases, bone alterations and the root morphology ${ }^{11}$.

When the PDL is overly compressed, it can cause cell death, creating a hyaline area, cementoblast layer damage and root resorption ${ }^{12}$. Hyaline areas in PDL will delay tooth movement and will facilitate the presence of root resorptions ${ }^{13-15}$

Root resorption during OTM is a frequent phenomenon, but must not be considered normal or physiological. In some orthodontic treatments, apical root resorption is inevitable, but predictive factors can be defined ${ }^{12-14}$. It will depend on the magnitude, duration and type of force, which may cause many degrees of root resorption ${ }^{16-18}$ in different root morphologies s,19,20. $^{10}$.

This study proposes to demonstrate the microscopic aspects of tooth movement in rats, by analyzing the hyaline areas in PDL and root resorptions in OTM, on roots with different types of morphology.

\section{Methods}

\section{Sampling}

The procedures of this research were performed in compliance with the ethical and legal recommendations specified by the Animals Ethics Commission (CEUA) of Fundação Hermínio Ometto - Uniararas (Report nº30/2013).

The research used Wistar rats (Rattus norvegicus, albinos), male, three month old. They were kept at temperature of $25^{\circ} \mathrm{C}$, in plastic cages and were provided food (Nuvilab, Quimtia S.A, Colombo/PR, Brazil) and water ad libitum.

Ten animals were divided into three groups. Group $G 3(n=5)$ : three days of orthodontic tooth movement (OTM), Group G7 ( $n=5)$ : seven days of orthodontic tooth movement (OTM) and Control Group ( $n=5)$ : contralateral teeth not moved of each animal.

\section{Orthodontic movement}

The animals were anesthetized with three parts of ketamine hydrochloride, $100 \mathrm{mg} / \mathrm{ml}$ (Cetamin, Syntec do Brasil Ltda, Cotia/SP, Brazil) one part of the xylazine hydrochloride, $20 \mathrm{mg} / \mathrm{ml}$ (Xilasin, Syntec do Brasil, Cotia/SP, Brazil) at the dose of $1 \mathrm{ml} / \mathrm{Kg}$, applied intramuscularly. 
A closed stainless steel spring was placed between the maxillary left first molar (point of force application) and the maxillary incisors (point of anchorage), tipping forward the first molar, applying $40 \mathrm{gf}$ (Figure 1) ${ }^{21}$.

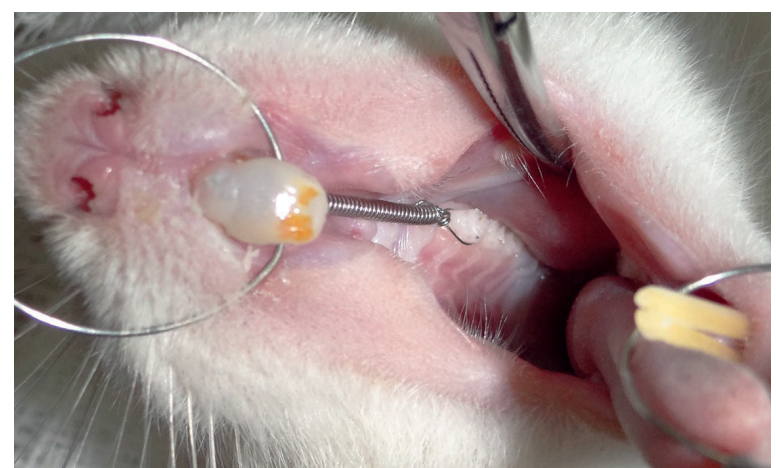

Figure 1. Device used in the movement of the first molar. Spring installed between the first molar and the incisors.

\section{Quantitative Histomorphometric Analysis}

The animals were euthanized with an overdose of the anesthetic ketamine and xylazine mixture. The maxillae were placed in a 10\% buffered formol solution for fixation during 2 days. They were demineralized with EDTA (monobasic sodium phosphate 4.4g; dibasic sodium phosphate 45g; EDTA 70g; Deionized $\mathrm{H}_{2} \mathrm{O}, 1000$ ml; Formaldehyde PA $50 \mathrm{ml}$ ) in a period of eight weeks.

The maxillae were embedded in paraffin and cut in transversal cross sections $(5 \mu \mathrm{m})$, stained with hematoxylin-eosin and the roots were analyzed in the cervical level22. The mesiovestibular (MV) and distovestibular (DV) roots were analyzed in optical microscope with an objective with 10x magnification (Zeiss KS 300, version 3.0). Five sections per animal were used for histomorphometrical quantification (Figure 2).
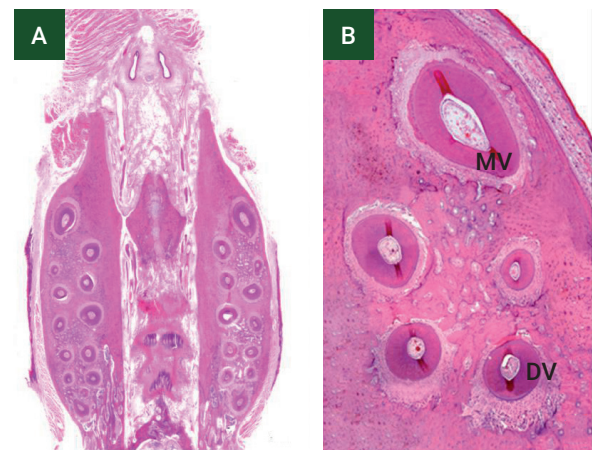

Figure 2. A - Microscopic cross section of the jaw (Staining - HE, magnification-4x). B - Microscopic cross section of the upper first molar, occlusal view. MV - mesiobuccal root. DV - distobuccal root (Staining - HE, magnification-10x). 
Division of hyaline area by the total PDL area gives the percentage of periodontal hyaline area (Figure 3). The percentage of root resorption was calculated at the same way, with the division of resorption area by the total root area (Figure 4).
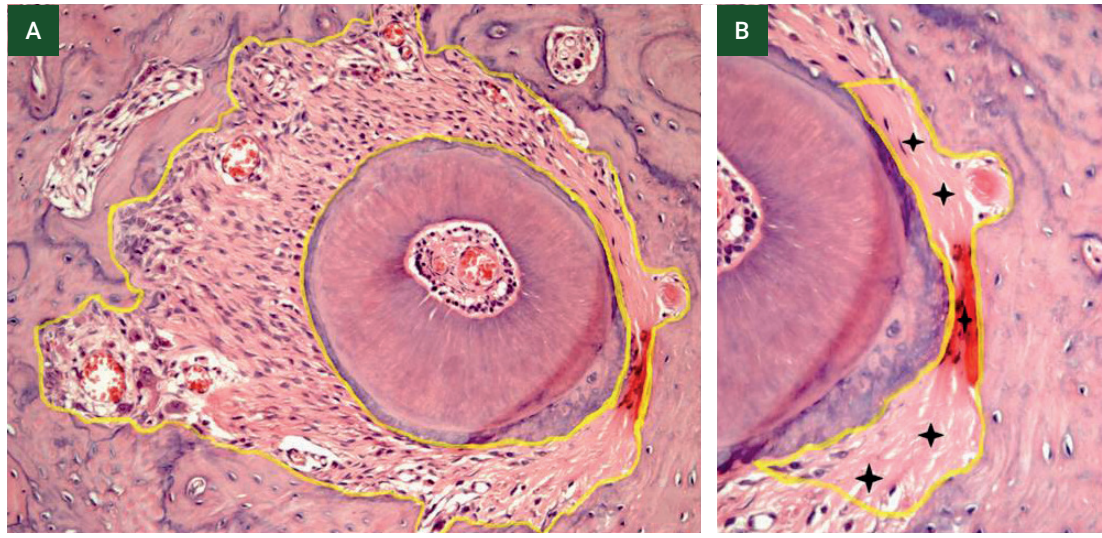

Figure 3. Cross section of distobuccal root (DV) with 3 days of orthodontic movement. A - Section area of the PDL. B - * Periodontal hyaline area (Staining - HE, magnification-40x).
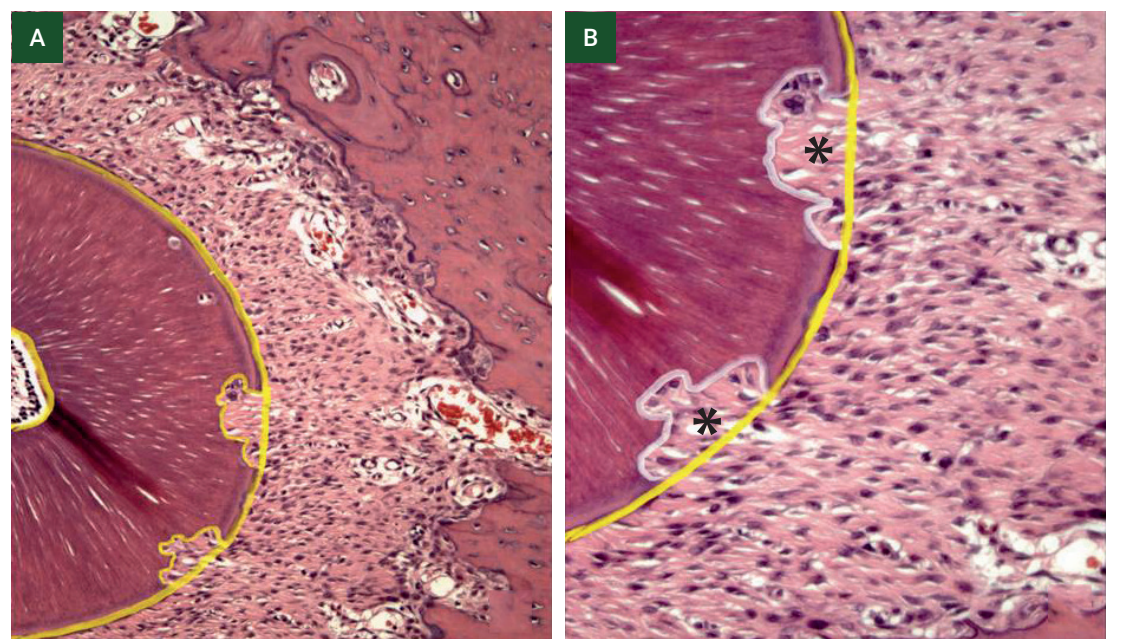

Figure 4. Cross section of distobuccal root (DV) with 7 days of orthodontic movement. A - Section area of the root, including cementum and dentin (Staining - HE, Lens - 4x). B - * Root resorption area (Staining - HE, magnification-40x).

The frequency of root resorption events was also verified in each animal by total in group $(n=5)$ in the different periods of OTM and roots.

The mean of hyaline area percentage of PDL and percentage of root resorption were compared by ANOVA and the Tukey post-test $(p<.05)$. 


\section{Results}

Hyaline area percentage in PDL and root resorption percentage, according to the OTM period and analyzed root are presented in Table 1.

Table 1. Mean of hyaline percentage area of PDL and percentage of root resorption, found in each group, according to the OTM period and root analyzed.

\begin{tabular}{lcccccc}
\hline \multirow{2}{*}{ Root } & \multicolumn{3}{c}{ Hyaline area (\%) } & \multicolumn{3}{c}{ Root resorptions area (\%) } \\
\cline { 2 - 7 } & Control & 3 days & 7 days & Control & 3 days & 7 days \\
\hline MV & 0 & 0 & 0 & 0 & 0 & 0 \\
\hline DV & 0 & $6.2^{*}$ & $1.8^{*}$ & 0 & 0 & $0.9^{*}$ \\
\hline
\end{tabular}

* Statistically significant compared to the Control Group on each root analyzed $(p \leq 0.05)$.

$\mathrm{MV}$ - mesiovestibular root.

DV - distovestibular root.

The MV root presented no segmental hyaline areas in PDL. There were hyaline areas in OTM Groups of the DV root, and were statistically significant in comparison of the Control and MV Groups ( $\mathrm{s} \leq 0.05)$. The hyaline areas were greater in $3^{\text {rd }}$ day (mean of $6.2 \%$ ) than in $7^{\text {th }}$ day (mean of $1.8 \%$ ). On MV root, there was no root resorption. On the DV root resorption appeared in the $7^{\text {th }}$ period of OTM (mean of $0.9 \%$ ).

The frequency of root resorption occurred in the period of 7 days of OTM. This frequency of root resorption was 3:5 (60\% of the animals) in the DV root (Table 2).

Table 2. Frequency of root resorption (animals by total in group), according to the OTM period and root analyzed.

\begin{tabular}{lccc}
\hline Root & Control & 3 days & 7 days \\
\hline MV & $(0: 5) 0 \%$ & $(0: 5) 0 \%$ & $(0: 5) 0 \%$ \\
DV & $(0: 5) 0 \%$ & $(0: 5) 0 \%$ & $(3: 5) 60 \%$ \\
\hline
\end{tabular}

\section{Discussion}

Animals as experimental models allows clinical reproducibility22. This in vivo research provides relevant data on physiological and pathological conditions that may be useful for establishing more effective clinical interventions ${ }^{23}$. Orthodontic tooth movement (OTM) causes resorption of alveolar bone on the compression side and osteogenesis on the tension side. Studies investigating the mechanisms involved in this process are important to improve orthodontic treatment ${ }^{24}$.

This OTM experimental design ${ }^{21}$, tips forward the first molar, without interfering on the rat craniofacial structure. It is efficient to study bone remodeling and root resorptions in Orthodontics. This model allowed studies such as auxiliary therapies ${ }^{25}$ and drug interference ${ }^{26}$ on bone remodeling in orthodontic movement.

Transversal sections give a direct view of the alveolar bone between the roots, and also allow evaluation of the cortical bone in the same section. Thus, all the struc- 
tures could be analyzed simultaneously, and compared with the same structures on the contralateral control side, without OTM, being an important control of the biologic reactions found. In the longitudinal sections it is not possible to visualize all the roots at the same time and neither to simultaneously analyze the different anatomic regions, such as cortical and medullary bone ${ }^{27}$.

Mesiovestibular (MV) and distovestibular (DV) roots are exposed to moderate forces and intense forces, respectively, during OTM. The root morphology has an influence on the orthodontic force intensity and PDL tissue reaction, and in the production of root resorptions.

In this research, two roots of the rat first molar were compared and evaluated simultaneously. The MV root, bigger, presented no root resorption. Bigger roots with larger dimensions present better distribution of the applied forces. This fact was confirmed given that no hyalinization of the PDL was found in the MV root in the OTM groups. The presence of hyalinized tissue within the PDL is a microscopic sign of excessive compression, resulting from the intense application of forces.

When these forces are intense and prolonged, the cells that line the tooth roots, the cementoblasts are injured. The cementoblasts protect the root surface, because they do not have receptors for the mediators that participate in bone remodeling ${ }^{12-14}$. The majority of external root resorptions, as an initial phenomenon, present large destruction of the layer of cementoblasts, denuding the mineralized dentin surface and exposing it to the action of the bone remodeling cells ${ }^{12-14}$. Therefore, excessive orthodontic forces may result in undesired root resorptions.

Root resorption could be seen with abundance in the DV root, in the period of 7 days of movement, in which the percentage and the frequency were greater than in the MV root. This result is explained because its morphology is smaller in comparison with those of the MV root. On the $3^{\text {th }}$ day of movement, there was clear evidence of the high incidence of forces on the mesial surface of this DV root, with the presence of large segmental PDL hyaline areas.

The results demonstrated the anatomic influence on root resorptions. The DV root dimension is smaller, with its conical shape, as in a single-rooted tooth, promoting greater pressure and less distribution of forces on PDL walls. Thus, smaller roots may present evident effects, such as root resorption and hyaline area, because they have poor ability to dissipate compressive force during tooth movement. ${ }^{20}$

\section{References}

1. Krishnan V, Davidovitch Z. Cellular, molecular, and tissue-level reactions to orthodontic force. Am J Orthod Dentofacial Orthop. 2006 Apr;129(4):469.e1-32.

2. Cattaneo PM, Dalstra M, Melsen B. Strains in periodontal ligament and alveolar bone associated with orthodontic tooth movement analyzed by finite element. Orthod Craniofac Res. 2009 May;12(2):120-8. doi: 10.1111/j.1601-6343.2009.01445.x.

3. Brezniak N, Wasserstein A. Orthodontically induced inflammatory root resorption. Part I: the basic science aspects. Angle Orthod. 2002 Apr;72(2):175-9. 
4. Cuoghi OA, Aiello CA, Consolaro A, Tondelli PM, Mendonça MR. Resorption of roots of different dimension induced by different types of forces. Braz Oral Res. 2014;28. pii: S1806-83242014000100231.

5. Dominguez A, Gómez C, Palma Jc. Effects of low-level laser therapy on orthodontics: rate of tooth movement, pain, and release of RANKL and OPG in GCF. Lasers Med Sci. 2015 Feb;30(2):915-23. doi: 10.1007/s10103-013-1508-x

6. Nimeri G, Kau CH, Abou-Kheir NS, Corona R. Acceleration of tooth movement during orthodontic treatment: A frontier in Orthodontics. Prog Orthod. 2013 Oct 29;14:42. doi: 10.1186/2196-1042-14-42

7. Olteanu CD, Mureşan A, Crăciun A, Şerbănescu A, Olteanu I, Keularts MI. [Determination of the level of interleukin-1beta and interleukin-8 in the gingival fluid of orthodontic tract teeth]. Fiziologia. 2009,19(4):8-12. Romeno.

8. Di Domenico M, D’Apuzzo F, Feola A, Cito L, Monsurrò A, Pierantoni GM, et al. Cytokines and VEGF induction in orthodontic movement in animal models. J Biomed Biotechnol. 2012;2012:201689 doi: $10.1155 / 2012 / 201689$

9. O’Brien CA; Nakashima T, Takayanagi H. Osteocyte control of osteoclastogenesis. Bone. 2013 Jun;54(2):258-63. doi: 10.1016/j.bone.2012.08.121.

10. Celebi AA, Demirer S, Catalbas B, Arikan S. Effect of ovarian activity on orthodontic tooth movement and gingival crevicular fluid levels of interleukin-1 $\beta$ and prostaglandin E(2) in cats. Angle Orthod. 2013 Jan;83(1):70-5. doi: 10.2319/012912-78.1

11. Norton LA, Burstone CJ. The biology of tooth movement. Boca Raton. CRC Press; 1989.

12. Maltha JC, van Leeuwen EJ, Dijkman GE, KuijpersJagtman AM. Incidence and severity of root resorption in orthodontically moved premolars in dogs. Orthod Craniofac Res. 2004 May;7(2):115-21.

13. Marques LS, Junior P, Jorge M, Paiva SM. Root Resorption in Orthodontics: An Evidence-Based Approach. In:Bourzgui F, organizator. Orthodontics - Basic Aspects and Clinical Considerations Sahngai: In Tech; 2012. p.429-46.

14. Lopatiene $\mathrm{K}$, Dumbravaite A. Risk factors of root resorption after orthodontic treatment. Stomatologija. 2008;10(3):89-95.

15. Seifi M, Eslami B, Saffar AS. The effect of prostaglandin E2 and calcium gluconate on orthodontic tooth movement and root resorption in rats. Eur J Orthod. 2003 Apr;25(2):199-204.

16. Kumasako-Haga T, Konoo T, Yamaguchi K, Hayashi H. Effect of 8-hour intermittent orthodontic force on osteoclasts and root resorption. Am J Orthod Dentofacial Orthop. 2009 Mar;135(3):278.e1-8; discussion 278-9. doi: 10.1016/j.ajodo.2008.11.007

17. Weltman B, Vig KWL, Fields HW, Shanker S, Kaizar EE. Root resorption associated with orthodontic tooth movement: a systematic review. Am J Orthod Dentofacial Orthop. 2010 Apr;137(4):462-76; discussion 12A. doi: 10.1016/j.ajodo.2009.06.021

18. Nakano T, Hotokezaka H, Hashimoto M, Sirisoontorn I, Arita K, Kurohama T,et.al. Effects of different types of tooth movement and force magnitudes on the amount of tooth movement and root resorption in rats. Angle Orthod. 2014 Nov;84(6):1079-85. doi: 10.2319/121913-929.1.

19. Ioannidou-Marathiotou I, Papadopoulos MA, Kokkas A. Orthodontic treatment and root resorption of teeth: critical analysis of mechanical factors. Hell Orthod Rev. 2010;13(1-2):25-42.

20. Cuoghi OA, Tondelli PM, Aiello CA, Mendonça MR, Costa SC. Importance of periodontal ligament thickness. Braz Oral Res. 2013 Jan-Feb;27(1):76-9

21. Santamaria M Jr, Milagres D, Stuani AS, Stuani MB, Ruellas AC. Initial changes in pulpal microvasculature during orthodontic tooth movement: a stereological study. Eur J Orthod. 2006 Jun;28(3):217-20 
22. Reitan K, Kvam E. Comparative behavior of human and animal tissue during experimental tooth movement. Angle Orthod. 1971 Jan;41(1):1-14.

23. Kim JH, Kim HW. Rat defect models for bone grafts and tissue engineered bone constructs. Tissue Eng Regen Med. 2013,10(6):310-6.

24. Van Schepdael A, Vander Sloten J, Geris L. A mechanobiological model of orthodontic tooth movement. Biomech Model Mechanobiol. 2013 Apr;12(2):249-65. doi: 10.1007/s10237-012-0396-5.

25. Spadari GS, Zaniboni E, Vedovello SA, Santamaria MP, do Amaral ME, Dos Santos GM, et al. Electrical stimulation enhances tissue reorganization during orthodontic tooth movement in rats. Clin Oral Investig. 2017 Jan;21(1):111-120. doi: 10.1007/s00784-016-1759-6.

26. Franzoni JS, Soares FMP, Zaniboni E, Vedovello Filho M, Santamaria MP, Dos Santos GMT, et al. Zoledronic acid and alendronate sodium and the implications in orthodontic movement. Orthod Craniofac Res. 2017 Aug;20(3):164-169. doi: 10.1111/ocr.12192.

27. Fracalossi ACC, Santamaria MJr, Consolaro MFMO, Consolaro A. [Experimental tooth movement in murines: study period and direction of microscopic sections]. Rev Dent Press Ortod Ortop Facial. 2009 Jan-Feb;14 (1):143-57. doi: 10.1590/S1415-54192009000100014. Portuguese. 